\title{
Anjiyografi Hasta Plazmalarında, Paraoxonase 1, Arylesterase ve Total Thiol İncelemesi
}

\author{
Paraoxonase1, Arylesterase and Total Thiol Investigation in Angiography Patient Plasmas \\ ${ }^{1}$ Hayrullah YAZAR, ${ }^{2}$ Güler Kuşçu GÜNAY, ${ }^{3}$ Mustafa Baran İNCİ, \\ ${ }^{4}$ Süleyman KALELİ, ${ }^{5}$ Mehmet Akif ÇAKAR \\ ${ }^{1}$ Sakarya Üniversitesi Tıp Fakültesi, Tıbbi Biyokimya, Sakarya, Türkiye \\ ${ }^{2}$ Sakarya Üniversitesi Sağlık Bilimleri Enstitüsü, Sakarya, Türkiye \\ ${ }^{3}$ Sağlık Bakanlığı, İstanbul Sağlık Müdürlüğü, Halk Sağlığı, İstanbul, Türkiye \\ ${ }^{4}$ Sakarya Üniversitesi Tıp Fakültesi, Tıbbi Biyoloji Anabilim Dalı, Sakarya, Türkiye \\ ${ }^{5}$ Sakarya Üniversitesi Tıp Fakültesi, Kardiyoloji Anabilim Dalı, Sakarya, Türkiye
}

Hayrullah Yazar: https://orcid.org/0000-0001-9447-6322

Güler Kuşçu Günay: https://orcid.org/0000-0002-5529-3061

Mustafa Baran İnci: https://orcid.org/0000-0003-1893-5368

Süleyman Kaleli: https://orcid.org/0000-0002-6043-2521

Mehmet Akif Çakar: https://orcid.org/0000-0003-3216-4205

\section{ÖZ}

Amaç: Radyal koroner anjiyografi uygulanan erişkin hastalarda; Paraoxonase-1 (PON 1), Arilesteraz (ARE) ve Total tiyol (TTL) değerlerinin, kan plazmasında tespit edilmesi amaçlandi.

Materyal ve Metot: Çalışmanın katılımcı sayısı, biris kontrol diğeri hasta grubu olmak üzere, iki grupta toplam 68 oldu. Kontrol grubu 34 sağlıklı bireyden oluşurken, hasta gurubu ise 34 radyal koroner anjiyografi hastasindan oluştu. Kan numuneleri lityum heparinli tüplere alındıktan sonra laboratuvara transfer edildi ve burada santrifüj işleminden sonra ayrılan plazmaları, çalıșma gününe kadar kapaklı ependorf tüplerde $-80 \mathrm{C} 0$ de sakland1. Test parametreleri tam otomatik analizörde spektrofotometrik metot ile incelendi. Çalışmada elde edilen veriler SPSS 23 paket programı ile istatistiksel olarak analiz edildi. Anlamlılık düzeyi, $\mathrm{p}<0, .05$ olarak kabul edildi.

Bulgular: Hasta grubundaki ortalama TTL değerleri $(360,29 \mu \mathrm{mol} / \mathrm{L})$ kontrol grubuna göre $(482,25 \mu \mathrm{mol} / \mathrm{L})$ anlamlı derecede düşük bulundu $(\mathrm{p}<0,001)$. Benzer şekilde hastaların ortalama ARE değerleri (11,30 U/L) kontrol grubuna göre $(14,28 \mathrm{U} / \mathrm{L})$ anlamlı derecede düşük bulundu $(\mathrm{p}<0,001)$. Hasta grubu PON 1 (U/L) değerleri sirasiyla (medyan, Q1, Q3): 140,78; 100,06; 322,12 olarak bulundu. Kontrol grubu PON $1(\mathrm{U} / \mathrm{L})$ değerleri ise, sirasıyla: 153,65; 104,9Q8; 454,13 şeklinde bulundu. Bu değerler arasında anlamlı bir fark olmadığı görüldü $(p=0,30)$.

Sonuç: Anjiyografi hastaları plazma değerleri, lipofilik antioksidan özelliklerde azalma olduğunu gösterdi. PON değerleri, istatistiksel olarak anlamlı olmamasına rağmen bu görüşü destekledi. Öte yandan; hasta grubunda tespit edilen anlamlı TTL düşüklüğü, üzerinde daha geniş araştırmalar gerektiren bir sonuç olarak tespit edildi.

Anahtar Kelimeler: Arilesteraz, paraoxonase 1, renal anjiyografi, total tiyol

\section{ABSTRACT}

Objective: In adult patients undergoing radial coronary angiography; It was aimed to determine the values of paraoxonase-1, Arylesterase and Total thiol in blood plasma.

Materials and Methods: The number of participants in the study was 68 in two groups, one for the control group and the other for the patient group. While the control group consisted of 34 healthy individuals, the patient group consisted of 34 radial coronary angiography patients. After blood samples were taken into lithium heparin tubes, they were transferred to the laboratory and the plasma separated after centrifugation was stored at $-80^{\circ} \mathrm{C}$ in capped eppendorf tubes until the working day. Test parameters were analyzed by spectrophotometry method on a fully automated analyzer. The data obtained in the study were statistically analyzed with the SPSS 23 package program. Significance level was accepted as $p<0.05$.

Results: The mean TTL values in the patient group $(360.29 \mu \mathrm{mol} / \mathrm{L})$ were found to be significantly lower than the control group $(482.25 \mu \mathrm{mol} / \mathrm{L})(\mathrm{p}<0.001)$. Similarly, the mean ARE values of the patients $(11.30 \mathrm{U} / \mathrm{L})$ were found to be significantly lower than the control group $(14.28 \mathrm{U} / \mathrm{L})(\mathrm{p}<0.001)$. Patient group PON 1 (U/L) values, respectively (median, Q1, Q3): 140.78; 100.06; 322.12 were found. Control group PON 1 (U/L) values: 153.65; 104.9Q8; 454.13 were found. There was no significant difference between these values $(\mathrm{p}=0.30)$.

Conclusion: Angiography patients showed a decrease in plasma values, lipophilic antioxidant properties. PON 1 values supported this view, although it was not statistically significant. On the other hand; Significant low TTL detected in the patient group was determined as a result that requires further studies.

Keywords: Arylesterase, paraoxonase 1, renal angiography, total thiol

\author{
Sorumlu Yazar / Corresponding Author: \\ Hayrullah Yazar \\ Sakarya Üniversitesi Tıp Fakültesi, Tıbbi Biyokimya, Sakarya, \\ Türkiye \\ Tel: 05323179702 \\ E-mail: drhyazar@hotmail.com
}

Yayın Bilgisi / Article Info:
Gönderi Tarihi/ Received: 29/03/2021
Kabul Tarihi/ Accepted: 13/01/2022
Online Yayın Tarihi/ Published: 01/03/2022 


\section{GíRiş}

Paraoksonaz (Pon) enzimi ile ilgili en geniş kapsam1 araştırma hiç kuşkusuz Diepgen TL ve arkadaşlarının yaptığı çalışmadır. ${ }^{1}$ Çalışma ile oldukça farklı ülkelerden toplanan insan serum örneklerinde Pon aktivitesi araştırılmıştır. Çalışmaya; Avrupa, Afrika ve Asya ülkeleri dahil edilmiştir. ${ }^{1}$ İlave olarak belirtmeliyiz ki; paraoksonaz 1 (PON 1) araştırmaları, özellikle, Macaristan'da gerçekleştirilen "Paraoksonazlar Konferansı" ile artmıştır. ${ }^{2}$ Konferansta Pon birçok hastalıkla ilişkilendirilmiş, bunlar arasında; kardiyovasküler hastalıklar, diabetes mellitus, romatizma, alzheimer yer almıştır. ${ }^{2}$ Günümüzde ise PON 1 araştırmaları, oldukça geniş bir yelpazede artarak devam etmektedir. $^{3-7}$

Arilesteraz (ARE) enzimi ile ilgili yapılan ilk çalışmalar içerisinde koyun plazmasında yapılan çalışma dikkat çekicidir. ${ }^{8}$ Yapılan araştırmada, "nişasta jel elektroforez" yoluyla farklı irkların koyunlarında kan plazma esterazları incelenmiş olup, esterazın en az üç enzimden oluşan bir "poli-enzim sistemi" olduğu gösterilmiştir. Bu enzimler; arilesteraz, karboksilesteraz ve kolin esteraz olarak ifade edilmiştir. ${ }^{8}$ Günümüzde yapılan araştırmalarda ARE ve PON 1 aktivitesi, lipit profilleri ile birlikte incelenmektedir. ${ }^{9}$

İnsan plazma Total tiyol (TTL) havuzunda miktar olarak en fazla albümin ve diğer proteinler vardır. Plazma TTL havuzunun küçük bir kısmında sistein, sisteinil glisin, glutatyon, homosistein ve $\gamma$ glutamilsistein gibi düşük molekül ağırlıklı tiyoller bulunmaktadır. ${ }^{10}$ Öte yandan; son yapılan araştırmalarda tiyollerin oksidatif stres ile ilişkileri tespit edilmiş olup, bu çalışmalar; çocuklardan hamile kadınlara kadar oldukça geniş bir yelpazede dikkat çekici sonuçlar ortaya koymuştur. ${ }^{11-13}$

Yapılan pek çok çalışmada gösterildiği gibi, koroner arter hastalığına (KAH) yol açan en önemli etken aterosklerozdur. Öte yandan; lipid profili bozukluğunun ateroskleroz ile ilişkisi de bilinen bir gerçektir. Dolayısıyla KAH riskinin teşhisi konusunda yapılan çalışmaların büyük kısmı kan lipitlerin düzeyi ile ilişkilidir. Ateroskleroza karşı korunmada rol oynayan yüksek yoğunluklu lipoprotein (HDL) ile ilişskili olan esteraz ise, PON 1 dir. ${ }^{14}$ PON 1 ve HDL kolesterol seviyesi ile KAH ilişkisi arasındaki son araştırmalar, PON 1 in daha iyi bir indikatör olduğunu göstermiştir. ${ }^{15}$ Bizim çalışmamızda, erişkinlerde, PON 1, ARE, TTL kan plazma değerleri; renal anjiyo yapılması gerekli görülen hastalar ile sağlıklı bireylerde karşılaştırılacaktır. Tespitlerimize göre çalışmamız literatürde ilk olma özelliğindedir; şöyle ki; PON 1, ARE ve TTL parametreleri, aynı anda anjiyo hastalarında ilk defa birlikte çalışılmıştır.

\section{MATERYAL VE METOT}

Etik Durum: Sakarya Üniversitesi Tıp Fakültesi Girişimsel Olmayan Etik Kurulundan izin alınan (Tarih:14.3.2018, karar no: 64) bu çalışma, SAÜ BAP (no: 12017-08-06-003) birimi tarafindan desteklenmiştir. Çalışmamız Uluslararası bildirgelerde ön görülen kriterlere göre yapılmıştır.

Yaklaşık 7 ay süren bu çalışmada, dahil edilen gönüllülerden aydınlatılmış onamlar alındı. Çalışmada kontrol grubu, gönüllü sağlıklı bireylerden oluşturuldu. Dahil edilme kriterleri: daha önceden dökümante koroner arter hastalığı öyküsü olmaması, kronik böbrek ya da karaciğer yetersizliği olmaması, son 1 y1l içerisinde serebrovasküler olay geçirmemesi, ciddi periferik arter hastalığı bulunmaması olarak belirlendi. Ayrıca; kontrolsüz diyabet ve hipertansiyon ile, klinik hipertroidi ve erektil disfonksiyon, dışlama kriteri olarak belirlendi. Çalışmada 34 kontrol ve 34 anjiografi hasta plazmas1; TTL, PON 1, ARE, tam otomatik analizörde incelendi (Beckman Coulter marka AU 680, seri no: 2016024580, Koutou-ku, Tokyo, Made In Japan). Kanlar tüm hastalardan yeşil kapaklı (lityum heparinli 4,5 cc, yeşil kapaklı BD) tüplere alındı ve numuneler derhal soğuk zincire uyularak transfer edildi. Laboratuvara gelen numuneler hemen santrifüj işlemine tabi tutularak (soğutmalı, 1500 g 10 dakika), kapaklı eppendorf tüplerde (isolab centrifuge tubes $2.0 \mathrm{ml}$ ) -80 de sakland1. Çalışmada, Rel Assay Diagnostics marka kit kullanıldı. Çalışma gününden 24 saat önce -80 deki numuneler -20 ye yerleştirildi, çalışmadan 1 saat önce -20 den çıkarılan numuneler mikro-santrifüj işlemine tabi tutuldu.

Ístatistiksel Analiz: Çalışmada elde edilen tüm verilere SPSS 23 paket programı uygulandı. Yapılan istatistiksel değerlendirmelerde; One Sample Kolmogorov Smirnov testi, Spearman korelasyon analizi, İndependent Samples T Testi ve Mann-Whitney $\mathrm{U}$ testi kullanıldı. Anlamlılık $\mathrm{p}<0,05$ düzeyinde değerlendirildi.

\section{BULGULAR}

Yapılan bu çalışmada; One Sample Kolmogorov Smirnov testine göre, ARE ve TTL değerleri normal dağılım gösterirken PON 1 değerleri normal dağılım göstermedi. Tanımlayıcı istatistikler sonucunda hasta $(n=34)$ ve kontrol grubundaki $(n=34)$ TTL değerlerinin aritmetik ortalama ve standart sapma değerleri sirasiyla $360,29 \pm 75,50 \mu \mathrm{mol} / \mathrm{L}$ ve $482,25 \pm 39,65$ $\mu \mathrm{mol} / \mathrm{L}$ olarak hesaplandi. Gruplarda, TTL ve ARE değerleri anlamlı bir fark gösterdi $(*$ : $p<0,05)$ (Tablo1).

Hasta ve kontrol grubundaki PON 1 değerlerinin aritmetik ortalama ve standart sapma değerleri sırasiyla $225,89 \pm 163,09 \mathrm{U} / \mathrm{L}$ ve $271,39 \pm 199,40 \mathrm{U} / \mathrm{L}$ olarak hesaplanırken, medyan değerleri sırasıyla 
140,78 U/L ve 153,65 U/L olarak hesaplandı (Şekil $1)$.

Tablo 1 ve Şekil 1'de gösterildiği gibi; hasta ve kontrol grubundaki ARE değerlerinin aritmetik ortalama ve standart sapma değerleri sirasiyla $11,30 \pm 2,88 \mathrm{U} / \mathrm{L}$ ve $14,28 \pm 2,49 \mathrm{U} / \mathrm{L}$ olarak hesaplandi. Spearman korelasyon analizinde TTL ile PON 1 değerleri arasında anlamlı bir ilişki saptanmazken PON 1 ile ARE değerleri arasında pozitif yönde, orta düzeyde istatiksel olarak anlamlı bir ilişki saptand $1(n=68, r=0,42, p<0,001)$. Ayrica, TTL ile ARE değerleri arasında pozitif yönde, güçlü düzeyde, istatiksel olarak anlamlı bir ilişki saptandı $(\mathrm{n}=68$, $\mathrm{r}=0,53, \mathrm{p}<0.001$ ). Hasta ve kontrol grubunun ARE ile TTL değerlerine İndependent Samples T Testi uygulandı. Yapılan Independent Samples T testinde, hasta grubundaki TTL değerleri (Ortalama \pm Stan- dart Sapma $=360,29 \pm 75,50 \mu \mathrm{mol} / \mathrm{L})$ kontrol grubuna göre (Ortalama \pm Standart Sapma $=482,25 \pm 39,65$ $\mu \mathrm{mol} / \mathrm{L})$ istatiksel olarak anlamlı derecede düşük bulundu $(\mathrm{p}<0,001)$. ARE değerleri, istatiksel olarak anlamlı derecede kontrol grubuna göre daha düşük bulundu. Hasta grubu Ortalama \pm Standart Sap$\mathrm{ma}=11,30 \pm 2,88 \mathrm{U} / \mathrm{L}$ iken, kontrol grubu Ortalama \pm Standart Sapma $=14,28 \pm 2,49$ U/L şeklinde oldu $(p<0,001)$. Hasta ve kontrol gruplarının normal dağılım göstermeyen PON 1 değerleri Mann-Whitney U testine göre değerlendirildi. Hasta grubu PON 1 (U/ L) değerleri sırasıyla (median, Q1, Q3): 140,78; 100,06; 322,12 olarak bulundu. Kontrol grubu PON 1 (U/L) değerleri ise, sirasıyla: 153,$65 ; 104,9 \mathrm{Q} 8$; 454,13 şeklinde bulundu. Hasta grubundaki PON 1 değerleri kontrol grubuna göre düşük bulunsa da, istatiksel olarak anlamlı değildi $(\mathrm{p}=0,30)$.

Tablo 1. TTL, ARE ve PON 1değer lerinin karşılaştır ması.

\begin{tabular}{|c|c|c|c|c|}
\hline & \multicolumn{2}{|c|}{ Hasta $(n=34)$} & Kontrol $(n=34)$ & $\mathbf{p}$ \\
\hline$\overline{T T L}(\mu \mathrm{mol} / \mathrm{L})$ & \multicolumn{2}{|c|}{$360,29 \pm 75,50$} & $482,25 \pm 39,65$ & $<0,001^{*}$ \\
\hline \multirow[t]{3}{*}{ PON 1 (U/L) } & Medyan & 140,78 & 153.65 & \multirow{3}{*}{$0,30 * *$} \\
\hline & Q1 & 100.06 & 104.98 & \\
\hline & Q3 & 322.12 & 454.13 & \\
\hline ARE(U/L) & & 2,88 & $14,28 \pm 2,49$ & $<0,001 *$ \\
\hline
\end{tabular}

*: İndependent Samples T testi uygulanmıştır. **: Hasta ve kontrol grupları normal dağılım göstermeyen PON 1 için Mann-Whitney U testi uygulanmıștır.

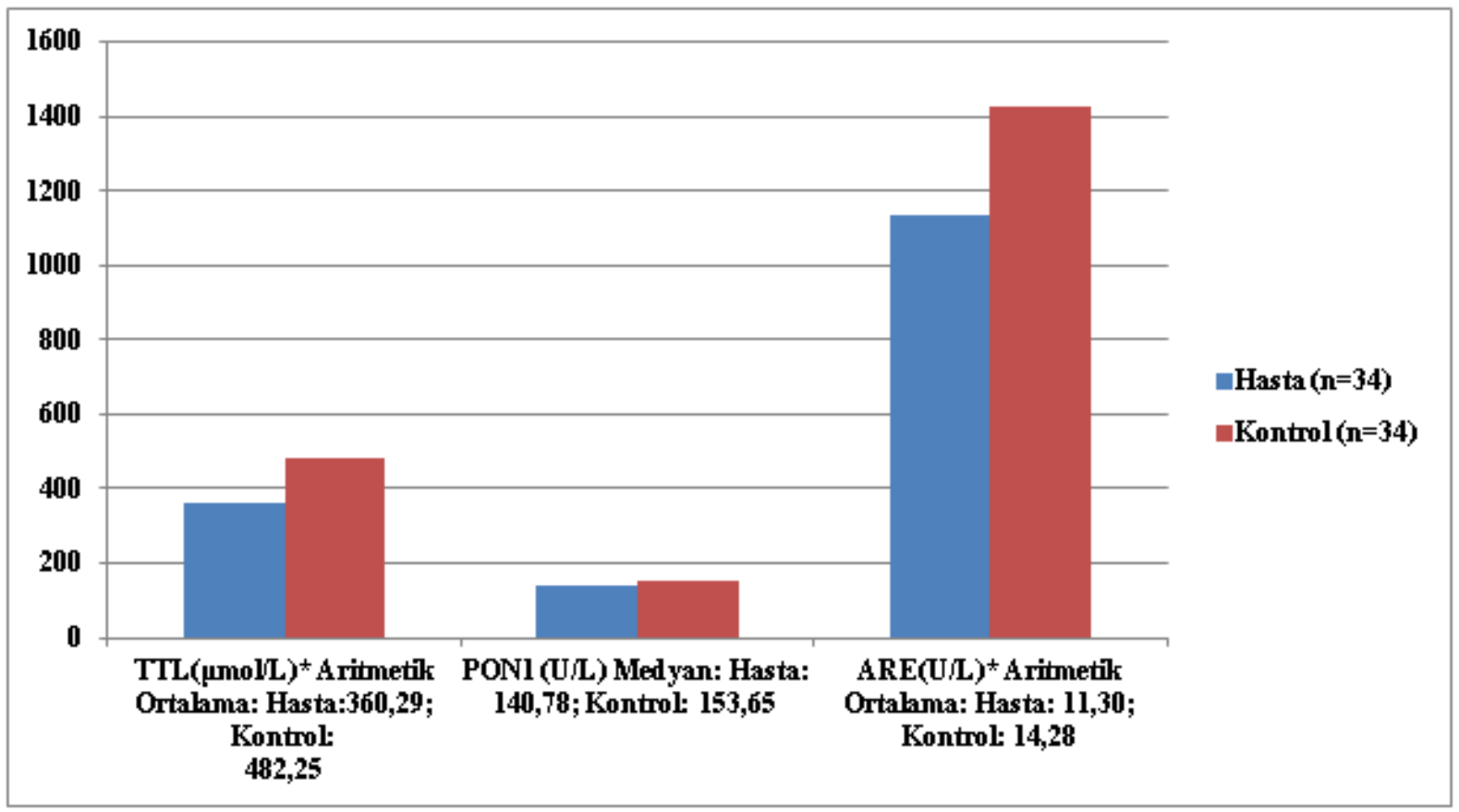

Şekil 1. TTL, ARE ve PON 1değerlerinin grafik üzerinde karşılaştırılması. 


\section{TARTIŞMA VE SONUÇ}

PON 1'in, ilaçlar ve bitki ekstraktları ile fizyolojik rolünü ve modülasyonunu anlamak için yapılan en yeni çalışmalar gözden geçirilmiştir. ${ }^{16}$ Yapılan incelemede; aterosklerozun Batı ülkelerinde önde gelen ölüm nedenlerinden biri olduğu vurgulanırken, düşük yoğunluklu lipoproteinlerin (LDL) oksidasyonunu engellemede HDL'nin önemli bir koruyucu rolü olduğu ifade edilmiştir. Yine aynı incelemede; HDL parçacıklarını oluşturan proteinlerden olan ARE ve PON 1'in, kardiyovasküler hastalıklardan muzdarip kişilerde önemli bir parametre olabileceği ve tedavi düzenlenmesine katkıda bulunabileceği ifade edilmiştir. ${ }^{16}$ Bizim çalışmamızda anjiyo hastalarında tespit edilen ARE sonuçlarındaki ciddi düşüklük $(p<0,001)$ bu yaklaşım ile uyumluluk göstermektedir. Öte yandan; çalışmamızda PON 1 düşüklüğü her ne kadar istatistiksel olarak anlamlı olmasa da, ifade edilen bilimsel tespitler ile örtüşmektedir.

Pon enziminin insan vücudunda antioksidan savunmanın evrensel faktörü olduğunu ifade edilmiştir. ${ }^{17}$ Pon'un gen ailesinin tandem olarak hizalandığı ve üç üyesinin tespit edildiği, bunların; PON 1, Pon2 ve Pon3 olduğu belirtilmiştir. Reaktif oksijen türlerindeki artan üretimin, ateroskleroz dahil olmak üzere birçok inflamatuar hastalığın gelişiminde rol oynadığ çalışmalarda bildirilmektedir. ${ }^{17-18}$ PON 1 ve Pon3 proteinlerinin; lipoproteinler, makrofajlar ve aterosklerotik lezyonlardaki bazı oksitlenmiş lipidleri hidrolize ederek, oksidatif strese karşı koruma sağlayabilecekleri ifade edilmiştir. ${ }^{17}$ Bizim araştırmamızda kontrol grubundaki sağlıklı bireylerde yüksek çıkan PON 1 değerleri de bu bakış açısı ile benzerlikler göstermektedir.

Stabil koroner arter hastalığ 1 tanısı konulan hastalarda yapılan bir başka çalışma ise, tıpkı bizim araştırmamız gibi, "anjiyo öncesinde göğüs ağrısı ve akut stres dönemi geçirilmiş olması" belirtecini kullanmıştır. ${ }^{18}$ Ayrıca çalışmada, diyabet olmayan hastaların seçilmesi, bizim araştırmamızda da kontrolsüz diyabeti olan hastaların dışlanması ile örtüşmektedir. ${ }^{18}$ Çalışmanın ortaya çıkardığ 1 ARE ve PON 1 aktivitesi düşüklüğü, bizim araştırmamız ile benzer nitelikte olup ateroskleroz ile ilişkilendirilmiştir. İlaveten, araştırmamızda tespit ettiğimiz ARE düşüklügü̈, bu ilişkiyi oldukça güçlü bir veri olarak desteklemektedir.

Koroner anjiyografi hastalarında doğal thiol/disülfid oranı ile koroner aterosklerozun şiddeti arasındaki ilişki araştırılmıştır. ${ }^{19}$ Yapılan çalışmada, koroner anjiyografi hastalarında spektrofotometrik tiyol ölçümünün $\% 73$ hassasiyet ve $\% 68$ özgüllük gösterdiği tespit edilmiştir. ${ }^{19}$ Öte yandan bizim araştırmamızda, anjiyografi hastalarında sadece tiyol ölçümü yapılmamış, ilaveten ARE ve PON 1 değerlerine de bakılmıştır. Ancak çalışmamızda aksidatif stres belirteçlerinin daha geniş kapsamlı test parametreleri ile birlikte incelenmemiş olması, hiç kuşkusuz sınırlılık oluşturmaktadır.

Sonuç olarak yapılan araştırmamızda; ARE plazma değerlerinin hasta grubunda anlamlı derecede düşük çıkması, anjiyo hastalarında lipofilik antioksidan özelliklerde azalma olduğunu göstermektedir. Nitekim, her ne kadar istatistiksel açıdan anlamlı olmasa da PON 1 düşüklüğü, bu görüşümüzü desteklemektedir. Yine çalışmanın bir başka sonucu olan hasta grubu TTL düşüklüğü, özellikle thiol/disülfid dengesinin içinde bulunduğu, daha geniş kapsamlı araştırmalara konu olacak nitelikte görülmektedir.

Etik Komite Onayı: Bu çalışmanın etik onayı, Sakarya Üniversitesi Tıp Fakültesi Etik Komitesinden alınmıştır (Tarih:14.3.2018, karar no: 64).

Çıkar Çatışması: Yazarlar çıkar çatışması bildirmemişlerdir.

Yazar Katkıları: Fikir - HY, GK.G.; Tasarım - HY, GKG, MBİ, MAÇ; Denetleme -HY, SK.; Veri Toplanması ve/veya İşlemesi - HY, GKG, MBİ, MAÇ; Analiz ve/veya HY, MBİ, SK.; Literatür Taraması - HY, GKG, SK.; Yazıyı Yazan - HY, GKG, MBI, SK.; Eleştirel İnceleme - HY, SK, MAÇ.

Hakem Değerlendirmesi: Dış bağımsız.

Finansal Destek: Bu makale Güler Kuşçu GÜNAY'ın yüksek lisans tezinden hazırlanmış olup, SAÜ BAP (no: 12017-08-06-003) tarafından desteklenmiştir.

\section{KAYNAKLAR}

1. Diepgen TL, Geldmacher MM. Interethnic differences in the detoxification of organophosphates: the human serum paraoxonase polymorphism. Arch Toxicol Suppl. 1986;9:154-158. doi:10.1007/978-3-642-71248-7_18

2. Bharti M, Mike M, Michael A, Gyorgy P. The paraoxonases: Their role in disease development and xenobiotic metabolism, proteins and cell regulation. Volume 6, Chapter 15: Springer Press; 2008:241-242.

3. Duni A, Liakopoulos V, Rapsomanikis KP, Dounousi E. Chronic kidney disease and disproportionally increased cardiovascular damage: Does oxidative stress explain the burden? Oxid Med Cell Longev. 2017;23(3):9036450. doi: $10.1155 / 2017 / 9036450$

4. Bacchetti T, Ferretti G, Sahebkar A. The role of paraoxonase in cancer. Semin Cancer Biol. Semin Cancer Biol. 2019;56:72-86. doi:10.1016/ j.semcancer.2017.11.013

5. Samouilidou E, Bountou E, Papandroulaki F, Papamanolis M, Papakostas D, Grapsa E. Serum endocan levels are associated with paraoxonase 1 
concentration in patients with chronic kidney disease. Ther Apher Dial. 2018;22(4):325-331. doi:10.1111/1744-9987.12654

6. Pavăl D, Nemeș B, Rusu RL, Dronca E. Genotype-phenotype analysis of paraoxonase 1 in schizophrenic patients treated with atypical antipsychotics. Clin Psychopharmacol Neurosci. 2018;16 (1):32-38. doi:10.9758/cpn.2018.16.1.32

7. Yeo KK, Armstrong EJ, López JE, et.al. Aspirin and clopidogrel high on-treatment platelet reactivity and genetic predictors in peripheral arterial disease. Catheter Cardiovasc Interv. 2018; 91 (7):1308-1317. doi:10.1002/ccd.27453

8. Glazko VI, Serov OL, Korochkin LI. Genetic control of the substrate specificity of sheep plasma arylesterase. Article in Russian. Genetika. 1975;11(2):79-86.

9. Cervellati C, Bonaccorsi G, Trentini A, et.al. Paraoxonase, arylesterase and lactonase activities of paraoxonase-1 (PON1) in obese and severely obese women. Scand J Clin Lab Invest. 2018;78 (1-2):18-24. doi:10.1080/00365513.2017.1405274

10. Yazar H, Halis F, Nasir Y, Guzel D, Akdogan M, Gokce A. Effect of the oxidant-antioxidant system in seminal plasma on varicocele and 1diopathic infertility in male humans. Clin Lab. 2017;63 (5):935-940. doi:10.7754/Clin.Lab.2016.161111

11. Yuvaci HU, Akdemir N, Bostanci MS, et.al. Evaluation of the level of thiol-disulphide homeostasis in patients with mild and severe preeclampsia. Pregnancy Hypertens. 2016;6(4):394-399. doi:10.1016/j.preghy.2016.09.003

12. Elmas B, Yildiz T, Yazar H, et.al. New oxidative stress markers useful in the diagnosis of acute appendicitis in children: thiol/disulfide homeostasis and the asymmetric dimethylarginine level. Pediatr Emerg Care. 2020;36(8):362-367. doi:10.1097/PEC.0000000000001339

13. Elmas B, Karacan M, Dervişoğlu P, Kösecik M, İşüven ŞP, Bal C. Dynamic thiol/disulphide homeostasis as a novel indicator of oxidative stress in obese children and its relationship with inflammatory-cardiovascular markers. Anatol J Cardiol. 2017;18(5):361-369. doi:10.14744/ AnatolJCardiol.2017.7740

14. Connelly PW1, Draganov D, Maguire GF. Paraoxonase-1 does not reduce or modify oxidation of phospholipids by peroxynitrite. Free Radic Biol Med. 2005;38(2):164-74. doi:10.1016/ j.freeradbiomed.2004.10.010

15. Singh K, Singh R, Chandra S, Tyagi S. Paraoxonase-1 is a better indicator than HDL of Atherosclerosis-A pilot study in North Indian population. Diabetes Metab Syndr. 2018;12 (3):275-278. doi:10.1016/j.dsx.2017.12.006

16. Moya C, Máñez S. Paraoxonases: metabolic role and pharmacological projection. Naunyn Schmiedebergs Arch Pharmacol. 2018;391(4):349-359. doi:10.1007/s00210-018-1473-9

17. Borovkova EI, Antipova NV, Komeenko TV, Shakhparonov MI, Borovkov IM. Paraoxonase: The universal factor of antioxidant defense in human body. Vestn Ross Akad Med Nauk. 2017;72(1):5-10. doi:10.15690/vramn764

18. Ding J, Chen Q, Zhuang X, Feng Z, Xu L, Chen F. Low paraoxonase 1 arylesterase activity and high von Willebrand factor levels are associated with severe coronary atherosclerosis in patients with non-diabetic stable coronary artery disease. Med Sci Monit. 2014;20:2421-2429. doi:10.12659/msm.890911

19. Kundi H, Erel Ö, Balun A, et.al. Association of thiol/disulfide ratio with syntax score in patients with NSTEMI. Scand Cardiovasc J. 2015;49 (2):95-100. doi:10.3109/14017431.2015.1013153 